\title{
Mitotic Chromosomal Process
}

National Cancer Institute

\section{Source}

National Cancer Institute. Mitotic Chromosomal Process. NCI Thesaurus. Code C51029.

A biological process that occurs during mitosis to ensure proper chromosomal numbers

in daughter cells. 